\title{
Medios de Cultivos Complejos para la Cuantificación de Bacterias Ácido Lácticas
}

\section{Karla Itzel Zacarías Sánchez,}

Egresada de Ingeniería en Alimentos, División Académica, Multidisciplinaria de los Ríos, Universidad Juárez Autónoma de Tabasco, México

\section{Francisco Rodríguez-Flores,}

Técnico Académico de Ingeniería en Alimentos, División Académica Multidisciplinaria de los Ríos, Universidad Juárez Autónoma de Tabasco, México

\section{Ana Laura Luna-Jiménez, Nicolás González-Cortés, Román Jiménez-Vera,}

Cuerpo Académico Desarrollo Sustentable, División Académica Multidisciplinaria de los Ríos, Universidad Juárez Autónoma de Tabasco, México

\section{Resumen}

El contenido de bacterias ácido lácticas (BAL) es un parámetro de calidad importante en los alimentos funcionales probióticos. Los medios de cultivo complejos formulados con aditivos naturales son una alternativa para su cuantificación. En este trabajo se propone el empleo de jugos de naranja, cebolla y chile jalapeño, pulpas de guayaba y de noni, así como leche en polvo como ingredientes de medios de cultivo complejos para la cuantificación de BAL. Se comparó la concentración de BAL recuperadas en los medios de cultivo complejos y el medio comercial para lactobacilos De Man, Rogosa y Sharpe (MRS). No se encontró diferencia significativa $(P<0.05)$ en la recuperación de BAL entre los medios de cultivo elaborados con jugo de naranja $(\log 9.33 \pm 0.05 \mathrm{UFC} / \mathrm{ml})$, pulpa de guayaba $(\log 9.20 \pm 0.10$ $\mathrm{UFC} / \mathrm{ml}$ ), pulpa de noni (Log $9.12 \pm 0.10 \mathrm{UFC} / \mathrm{ml})$, leche en polvo (Log 9.10 $\pm 0.15 \mathrm{UFC} / \mathrm{ml})$ y MRS (Log $9.20 \pm 0.22 \mathrm{UFC} / \mathrm{ml})$. Sin embargo, el recuento fue menor en los medios adicionados con cebolla y chile jalapeño. Los medios de cultivo complejos son una alternativa sencilla, económica y de calidad para la cuantificación de BAL en alimentos funcionales probióticos, como los lácteos fermentados y el yogur. 
Palabras clave: Medios complejos, Bacterias lácticas, Probióticos, microbiológico

\title{
Complex Culture Media for the Quantification of Lactic Acid Bacteria
}

\section{Karla Itzel Zacarías Sánchez,}

Egresada de Ingeniería en Alimentos, División Académica, Multidisciplinaria de los Ríos, Universidad Juárez Autónoma de Tabasco, México

Francisco Rodríguez-Flores, Técnico Académico de Ingeniería en Alimentos, División Académica Multidisciplinaria de los Ríos, Universidad Juárez Autónoma de Tabasco, México

\section{Ana Laura Luna-Jiménez, Nicolás González-Cortés, Román Jiménez-Vera,} Cuerpo Académico Desarrollo Sustentable, División Académica Multidisciplinaria de los Ríos, Universidad Juárez Autónoma de Tabasco, México

\begin{abstract}
The content of lactic acid bacteria (LAB) is an important quality parameter in probiotic functional foods. Complex culture media formulated with natural additives are an alternative for their quantification. In this work we propose the use of orange, onion and jalapeño pepper juices, guava and noni pulps, as well as milk powder as ingredients of complex culture media for BAL quantification. The concentration of BAL recovered in the complex culture media and the commercial medium for lactobacilli De Man, Rogosa and Sharpe (MRS) were compared. No significant difference was found $(P<$ $0.05)$ in BAL recovery between culture media made with orange juice (Log $9.33 \pm 0.05 \mathrm{CFU} / \mathrm{mL})$, guava pulp $(\log 9.20 \pm 0.10 \mathrm{CFU} / \mathrm{mL})$, pulp noni $(\log$ $9.12 \pm 0.10 \mathrm{CFU} / \mathrm{mL})$, milk powder $(\log 9.10 \pm 0.15 \mathrm{CFU} / \mathrm{mL})$ and $\mathrm{MRS}(\log$ $9.20 \pm 0.22 \mathrm{CFU} / \mathrm{mL}$ ). However, the count was lower in the media added with onion and jalapeño pepper. Complex culture media are a simple, economical and quality alternative for the quantification of BAL in functional probiotic foods, such as fermented milk products and yogurt.
\end{abstract}


Keywords: Complex media, Lactic bacteria, Probiotics, Microbiological

\section{Introducción}

El contenido de bacterias vivas es uno de los parámetros de calidad importante en alimentos funcionales probióticos, ya que el efecto en el equilibrio de la microflora intestinal está relacionado con la concentración de bacterias ácido lácticas. Existen medios de cultivo comerciales orientados al aislamiento y cuantificación de lactobacilos como MRS (Man et al., 1990), Rogosa (Tamime et al., 1995) y LAMVAB (Hartemink et al., 1997). También se han propuesto otros medios de cultivo selectivos empleados en investigación, como el evaluado por Di Lena et al. (2015) para detectar cuantitativamente y aislar cepas del grupo casei en leche y quesos probióticos, así como diversas variantes del medio MRS, con diferentes fuentes de carbono y proteínas (Lima et al., 2009).

La importación de medios de cultivo selectivos lleva tiempo y suelen ser caros, lo que hace prohibitivo su uso rutinario en muchos laboratorios de investigación (Lopes y Torres, 2006). La disponibilidad del medio MRS en algunos mercados no es inmediata. Por otra parte, en su composición se emplea una gran cantidad de constituyentes, lo que dificulta su elaboración en el laboratorio, ya que no todos los componentes están disponibles comercialmente.

Los medios de cultivo complejos o naturales están constituidos por sustancias complejas de origen animal o vegetal. En ellos no se conocen todos los componentes, ni las cantidades exactas presentes de cada uno de ellos. Como sustrato para el crecimiento de bacterias ácido lácticas se han empleado diversas fuentes naturales, León-de la $\mathrm{O}$ et al. (2013) realizaron la formulación y optimización de un medio de cultivo económico para Lactobacillus empleando formulaciones de leche y suero de leche; Brantes (2011) diseñó un medio de cultivo para la cepa BAL-C, productora de bacteriocina y obtuvo un medio más económico que el MRS donde se reemplazaron las fuentes de carbono y de micronutrientes por melaza, sacarosa, extracto de harina de pescado y extracto de harina de lupino. De igual manera, se ha evaluado la harina de leguminosas (Pathak y Martirosyan, 2012) y la yema de huevo (Djeghri-Hocine et al., 2010) como aditivos de medios de cultivo para bacterias probióticas.

Bujalance et al. (2006) desarrollaron un medio selectivo y diferencial (LPSM), para el aislamiento de Lactobacillus plantarum en muestras fecales. Por su parte, Chen et al. (2015), optimizaron un medio para Lactobacillus acidophilus, mediante la selección de la fuente de carbono (glucosa, maltosa, lactosa y suero en polvo) y la fuente de nitrógeno (caseína, peptona, extracto de levadura en polvo, harina de pescado, carbamida, sulfato de amonio y 
nitrato de sodio) que produzca el mayor crecimiento. De igual manera, Pathak y Martirosyan (2012) transformaron el medio MRS en un medio de cultivo complejo, mediante la agregación de extracto de polvo de semilla vegetal en sustitución del extracto animal para favorecer el crecimiento de probióticos presentes en alimentos veganos.

El objetivo de este trabajo fue evaluar medios de cultivo microbianos complejos suplementados con jugo de naranja, cebolla y chile jalapeño, pulpas de guayaba y noni y leche en polvo, para el aislamiento y cuantificación de bacterias ácido lácticas. El desarrollo de estos medios permitirá implementar métodos sencillos de cuantificación de bacterias lácticas en laboratorios con un volumen pequeño de muestras y económicos.

\section{Materiales y Métodos}

Materia prima. Se utilizaron naranjas dulces (Citrus sinensis) con un índice de madurez mayor a $12{ }^{\circ}$ Brix de acuerdo a la recomendación de Moreno et al. (2006), cebollas (Allium cepa L.) variedad morada de calidad México 1, clasificada por la norma NMX-FF-021-1986, chiles jalapeños (Capsicum annuиm L.) de primera calidad de acuerdo a la clasificación de la NMX-FF025-SCFI-2007 Sáenz y D’Alolio (2007), guayabas (Psidium guajava) con un índice de madurez mayor de $12.0^{\circ}$ Brix (Silva et al., 2006), frutos de noni maduros (Morinda citrifolia L.) y leche en polvo (Nestlēß) adquiridos en un supermercado local. La formulación también incluyó peptona de caseína (BXP-252606, Bioxon®), extracto de levadura (BXP-230900, Bioxon®), agar bacteriológico (Cat. 215000, Bioxon®) y glucosa (1083370250, Merck®). Como medio de referencia comercial se utilizó el agar MRS (1267-A, Dibico®)

Formulación de medios de cultivo. El agar jugo de naranja se preparó de acuerdo a la metodología propuesta por NORMEX (2002). Los agares de guayaba, cebolla, chile jalapeño y noni se elaboraron con la formulación propuesta por Urcia y Guevara (2002); el jugo de cebolla y chile se obtuvo mediante un extractor de jugo casero, las guayabas se sometieron a cocción durante $15 \mathrm{~min}$; tanto las guayabas como las frutas de noni se tamizaron en malla 50 para obtener una pulpa. El agar leche se elaboró de acuerdo a la metodología propuesta por Olivas y Alarcón (2004). Todos los medios de cultivo se esterilizaron en autoclave durante $15 \mathrm{~min}$ a $121^{\circ} \mathrm{C}$, se incubaron a $37{ }^{\circ} \mathrm{C}$ durante $24 \mathrm{~h}$ para evaluar su esterilidad y se almacenaron en refrigeración. El Cuadro 1 muestra la composición de los medios de cultivo para preparar $1000 \mathrm{ml}$. 
Cuadro 1. Formulación de los medios de cultivo complejos $(1000 \mathrm{ml})$.

\begin{tabular}{ccccccc}
\hline Componentes & $\begin{array}{c}\text { Agar jugo de } \\
\text { naranja }\end{array}$ & $\begin{array}{c}\text { Agar jugo de } \\
\text { cebolla }\end{array}$ & $\begin{array}{c}\text { Agar jugo } \\
\text { de chile }\end{array}$ & $\begin{array}{c}\text { Agar pulpa de } \\
\text { guayaba }\end{array}$ & $\begin{array}{c}\text { Agar pulpa } \\
\text { de noni }\end{array}$ & Agar leche \\
\hline $\begin{array}{c}\text { Peptona de caseína } \\
\text { (g) }\end{array}$ & 10 & 5 & 5 & 5 & 5 & 5 \\
$\begin{array}{c}\text { Extracto de } \\
\text { levadura (g) } \\
\text { Agar }\end{array}$ & 3 & 3 & 3 & 3 & 3 & 3 \\
$\begin{array}{c}\text { bacteriológico (g) } \\
\text { Glucosa (g) }\end{array}$ & 15.5 & 14 & 14 & 14 & 14 & 12 \\
$\begin{array}{c}\text { Leche en polvo (g) } \\
\text { Jugo natural (ml) }\end{array}$ & 10 & 5 & 5 & & & 1 \\
Pulpa de frutas (g) & & & & 5 & 5 & \\
\hline
\end{tabular}

\section{Cuantificación bacteriológica}

La concentración bacteriana se cuantificó a tres niveles: a) empleando una cepa de Lactobacillus casei Shirota contenida en caldo MRS (Dibico®) como microorganismo puro; b) evaluando una bacteria contenida en una matriz líquida, se cuantificó la concentración de bacterias contenida en el producto comercial Yakult ${ }^{\circledR}$ y; c) evaluando la concentración de una bacteria contenida en una matriz semisólida, se cuantificó la concentración de BAL contenidas en el producto comercial Danone ${ }^{\circledR}$ natural. La concentración de BAL se cuantificó por el micrométodo propuesto por Corona y Jiménez (2004). Se incubaron a $37{ }^{\circ} \mathrm{C}$ durante $48 \mathrm{~h}$ en bolsa anaerobia (Rosenblatt y Stewart, 1975).

\section{Resultados}

Los medios de cultivo complejos son aquellos donde no se conoce la composición exacta de los constituyentes, también se conocen como medios indefinidos o naturales. En este trabajo se evaluaron seis medios de cultivos complejos adicionados con jugos de naranja, cebolla y chile jalapeño, pulpas de guayaba y de noni, así como leche en polvo. Estos medios se compararon con el agar comercial MRS, empleado para el aislamiento de bacterias ácido lácticas. El Cuadro 2 muestra el crecimiento $\left(\log _{10} \mathrm{UFC} / \mathrm{ml}\right)$ de bacterias ácido lácticas en los diferentes medios de cultivo.

Cuadro 2. Recuperación de bacterias ácido lácticas en medios de cultivo naturales.

\begin{tabular}{lccc}
\hline \multicolumn{1}{c}{ Agar } & $\begin{array}{c}\text { Cepa pura } \\
\left(\log _{10} \mathrm{UFC} / \mathrm{ml}\right)\end{array}$ & $\begin{array}{c}\text { Matriz líquida } \\
\left(\log _{10} \mathrm{UFC} / \mathrm{ml}\right)\end{array}$ & $\begin{array}{c}\text { Matriz semisólida } \\
\left(\log _{10} \text { UFC/ml }\right)\end{array}$ \\
\hline Agar MRS & $4.24 \pm 0.34 \mathrm{a}$ & $6.89 \pm 0.27 \mathrm{~b}$ & $9.20 \pm 0.22 \mathrm{c}$ \\
Agar jugo de naranja & $4.74 \pm 0.06 \mathrm{a}$ & $6.95 \pm 0.08 \mathrm{~b}$ & $9.33 \pm 0.05 \mathrm{c}$ \\
Agar jugo de cebolla & $4.34 \pm 0.02 \mathrm{a}$ & $5.38 \pm 0.11 \mathrm{a}$ & $\mathrm{NE}$ \\
Agar jugo de chile & $4.28 \pm 0.70 \mathrm{a}$ & $5.49 \pm 0.80 \mathrm{a}$ & $\mathrm{NE}$ \\
Agar pulpa de guayaba & $4.42 \pm 0.10 \mathrm{a}$ & $6.83 \pm 0.19 \mathrm{~b}$ & $9.20 \pm 0.10 \mathrm{c}$ \\
Agar pulpa de noni & $6.62 \pm 0.15 \mathrm{~b}$ & $6.95 \pm 0.25 \mathrm{~b}$ & $9.12 \pm 0.10 \mathrm{c}$ \\
Agar leche & $6.74 \pm 0.06 \mathrm{~b}$ & $6.69 \pm 0.30 \mathrm{~b}$ & $9.10 \pm 0.15 \mathrm{c}$ \\
\hline
\end{tabular}

Letras diferentes indican diferencia estadística significativa $(P<0.05)$. NE $=$ No evaluado. 
La Figura 1 muestra la concentración de bacterias ácido lácticas obtenidas en los medios complejos experimentales, así como en el medio MRS. En la cuantificación de la cepa pura, la mayor recuperación bacteriana se obtuvo con el agar leche y el agar noni, mientras que con los otros medios se obtuvo una concentración sin diferencias con el agar MRS.

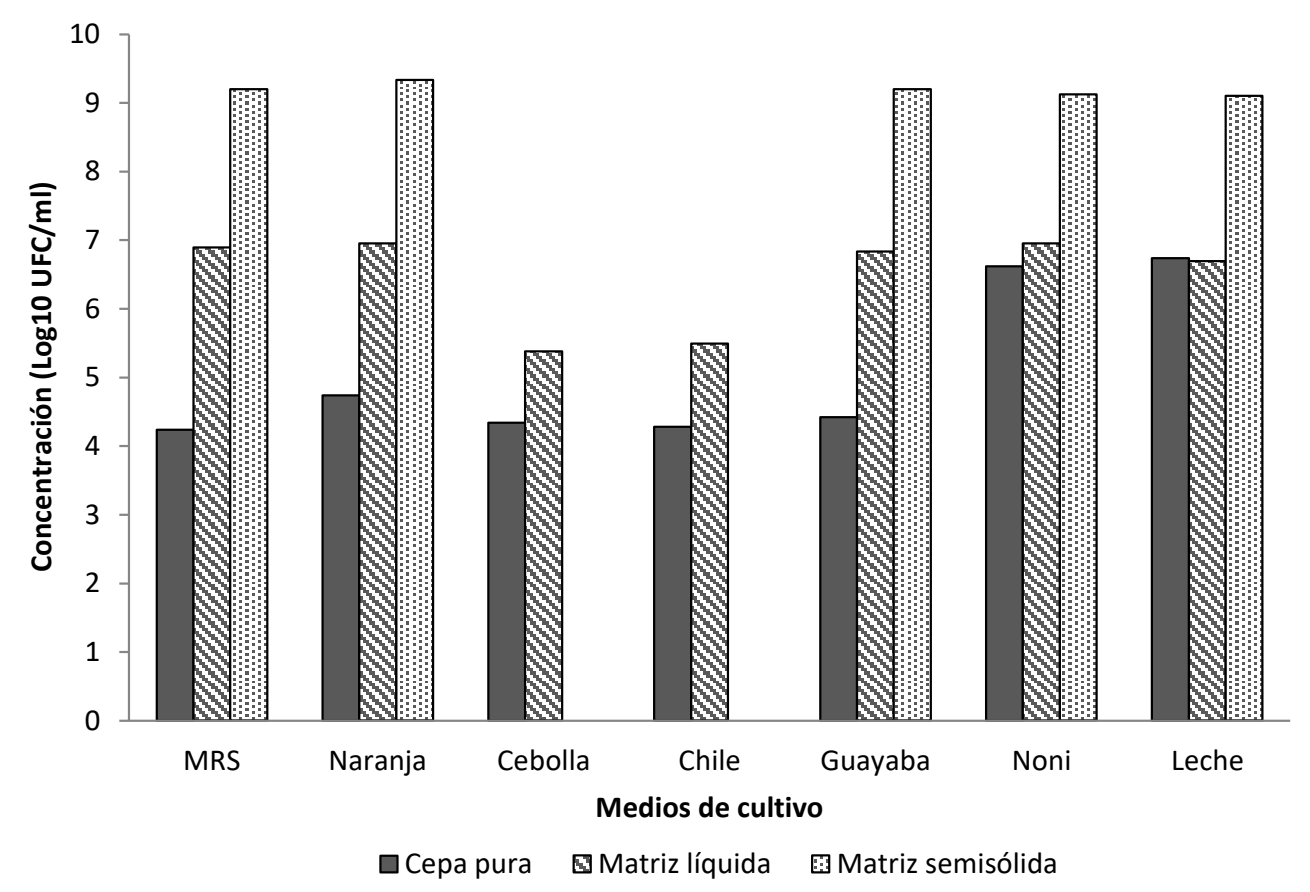

Figura 1. Crecimiento de Lactobacillus casei Shirota en medios complejos y MRS.

Los resultados obtenidos en el agar leche, pueden estar relacionados con la concentración de prebióticos presentes en la leche, como lactosa, galactooligosacáridos y lactulosa. La lactosa es el principal carbohidrato de la leche (47\%) constituido por glucosa y galactosa; es el principal sustrato lácteo utilizado por los microorganismos ácido lácticos como fuente de carbono para la formación de ácidos (Marcia et al., 2011). En un estudio realizado por Rojas et al. (2015) determinaron las condiciones para el crecimiento de Lactobacillus delbrueckii subsp. bulgaricus y Streptococcus thermophilus para la producción de ácido láctico, utilizando lactosuero como sustrato. Benaissa et al. (2017) evaluaron el suero de leche dulce como medio base para el cultivo de bacterias de ácido láctico y su efecto sobre las características tecnológicas de los lactobacilos, lo que presenta la oportunidad de desarrollar un medio de crecimiento bacteriano a bajo costo. Varios derivados de la lactosa, como la lactulosa, lactitol y lactosucrosa actúan como prebióticos y sus actividades bioquímicas se expresan en presencia de probióticos (Ugarte et al., 2011; Nath et al., 2017). 
También se ha demostrado que los galactooligosacáridos, componentes de la leche, son carbohidratos con actividad prebiótica que permiten cambios específicos en la composición y actividad de la microbiota intestinal responsable del bienestar y de la salud de su hospedador. Estos compuestos no son digeridos por el humano y por tanto llegan intactos hasta el colon donde sirven de alimento para bacterias benéficas; este efecto se conoce como bifidogénico, específicamente para bifidobacterias (Islam, 2013). El efecto prebiótico que presentan las sustancias contenidas en la leche, influyen para incrementar el número de BAL recuperadas.

También con el agar de pulpa de noni se obtuvo una alta recuperación bacteriana. En estudios cualitativos, se ha demostrado la presencia de azúcares, principalmente oligosacáridos, los cuales se ha demostrado poseen efecto prebiótico al estimular el crecimiento de lactobacilos y bifidobacterias (Bu et al., 2011). Otro componente que pudo influir en el crecimiento de los lactobacilos en el agar noni fue la concentración de proteínas. El noni, al igual que la leche, contiene $90 \%$ de agua y los componentes mayoritarios de la materia seca son sólidos solubles, fibra dietética y proteínas. El contenido proteínico de la fruta es de $11.3 \%$ de la materia seca del jugo y los principales aminoácidos son el ácido aspártico, el ácido glutámico y la isoleucina (Ulloa, 2012).

En cuanto a la recuperación en una matriz líquida, como los productos fermentados, es importante analizar la interferencia causada por el alimento que contiene a los microorganismos, ya que hay métodos de detección de microorganismos donde la matriz constituye una barrera para su identificación (Tabasco et al., 2007). En estas condiciones, se obtuvo la mayor recuperación con el agar naranja, seguido del agar guayaba y, la menor concentración, con los agares de cebolla y chile jalapeño. Aunque los medios con naranja, guayaba, noni y leche presentaron valores elevados de recuperación, no se encontró diferencias entre ellos y el medio comercial.

En relación al jugo de naranja, se ha reportado su uso en la elaboración de medios de cultivo para la determinación de folatos. Para esta determinación se emplean medios de cultivo de difícil adquisición por ser importados. En los últimos años, se dificultó la adquisición del medio, lo que obligó a desarrollar uno con las características que permitieran desarrollar la determinación. Este medio se obtuvo a partir de la modificación de un medio de cultivo comercial empleando jugo de naranja, llamado Citrufol-Hi®. Al igual que el agar naranja evaluado en este trabajo, la producción de Citrufol-Hi puede realizarse fácilmente y en pequeñas cantidades de acuerdo con las necesidades, evitando las pérdidas por deterioro, lo que hace de este, un reactivo con posibilidades de generalización (Forellat et al., 2004).

La recuperación de BAL en el medio con jugo de naranja puede estar relacionada con la mayor concentración de azúcares presentes, así como con 
la variedad de azúcares. Los microorganismos heterótrofos utilizan como fuente de carbono muchas moléculas orgánicas diferentes. Se ha reportado que el jugo de naranja fresco contiene sacarosa, glucosa y fructosa que en conjunto constituyen el $75 \%$ de los sólidos solubles totales; la concentración de fructosa en el jugo de naranja se encuentra entre el 40 y $45 \%$ de los sólidos (Chanson-Rolle et al., 2016).

En jugo de naranja se ha reportado una concentración de $8.46 \%$ de azúcares totales, correspondiendo a fructosa $1.93 \%$, glucosa $1.98 \%$ y sacarosa $4.6 \%$ (Chanson-Rolle et al., 2016). En un estudio realizado por Hours et al. (2005) se reportan los valores obtenidos en jugos de diferentes variedades. Estos azúcares constituyeron una buena fuente de carbono para el crecimiento de los lactobacilos, ya que, aunque el azúcar principal del jugo de naranja fue la sacarosa, también la glucosa y fructosa se encontraron en una concentración importante. Además, en este trabajo, fue el único medio de cultivo complejo, que, de acuerdo a su formulación, se le adicionó glucosa. En evaluaciones futuras, los medios adicionados con cebolla y chile jalapeño, donde se obtuvo la menor recuperación de microorganismos, pueden ser evaluados empleando glucosa como fuente de carbono.

La cebolla cuenta con un contenido de agua entre 87 y un $94 \%$, proteínas entre 0.5 y $1.4 \%$ y carbohidratos entre 4.5 a $10 \%$ (Jerez et al., 2017). Probablemente, los resultados se relacionan con la variedad de cebolla utilizada, ya que Liguori et al. (2017) reportan un alto contenido de fructosa, la glucosa la sacarosa se encontraron como azúcares solubles, siendo la fructosa el más abundante en la cebolla blanca. Por otra parte, de este bulbo se han aislado bacterias de ácido láctico, Shafakatullah y Chandra (2015) identificaron cuatro microorganismos y evaluaron sus propiedades probióticas: Bacillus coagulans (Lactobacillus sporogenes), Lactobacillus brevis, Lactobacillus delbrueckii subsp. bulgaricus y Lactococcus lactis.

En la matriz semisólida se evaluaron los medios con mayor recuperación: agar naranja, guayaba, noni y leche. En esta determinación, no se encontró diferencia significativa en la concentración de bacterias ácido lácticas recuperadas. El yogur contiene proteínas, grasas y carbohidratos que son propios de la leche, y debe contenerlos en las cantidades correspondientes al tipo de leche con que se elabora. Los azúcares son la base de los productos lácteos fermentados porque proporcionan energía a los microorganismos encargados de producir el sabor y el aroma de productos como el yogur (Zapata et al., 2015). Se encontró que las sustancias que conforman el yogur no interfirieron en la cuantificación de los microorganismos.

La alta recuperación de bacterias ácido lácticas obtenida con el agar de pulpa de guayaba se relaciona con información reportada sobre su capacidad de incrementar el crecimiento de BAL. En un estudio realizado por Buriti et al. (2007), evaluaron la sobrevivencia de Labbacillus acidophilus en mousse 
congelado. A los 21 días, la población probiótica permaneció por encima de Log 6.00 UFC/ml en el producto con guayaba. La adición de frutas a los productos probióticos puede mantener la viabilidad de las cepas probióticas. Lara (2008) mediante jugo de guayaba agria elaboró un medio de cultivo para el aislamiento y mantenimiento de microorganismos ruminales y del estiércol. Estos resultados confirman el efecto de la pulpa de guayaba en la recuperación de BAL en los medios de cultivo complejos.

Los medios complejos fueron los primeros medios de cultivo utilizados; los más empleados se preparan a partir de tejidos animales y vegetales. Su composición no es exactamente definida, y por consiguiente no es rigurosamente constante. Esto puede tener ciertos inconvenientes en condiciones experimentales, donde la reproductibilidad no podrá ser exacta. Sin embargo, en la práctica corriente estos medios dan excelentes resultados y son los más empleados (Casado et al., 2012).

\section{Conclusión}

Los medios de cultivo complejos con constituyentes naturales como el jugo de naranja, leche en polvo, pulpa de guayaba y pulpa noni poseen igual capacidad de cuantificación de bacterias ácido lácticas que el agar comercial de Man Rogosa y Sharpe. Aunque la cebolla y el chile han sido publicados como sustancias con capacidad prebiótica, su efecto en la cuantificación de bacterias lácticas se encontró por debajo del medio comercial de referencia. La matriz en donde se encuentran contenidas las bacterias lácticas no mostró interferencia en su recuperación. Los medios complejos con ingredientes naturales son una opción para el control de calidad en la cuantificación de bacterias ácido lácticas de productos lácteos fermentados y yogur.

\section{References:}

1. Benaissa, M., Zadi-Karam, H. \& Karam, N. (2017). Development of a sweet whey-based medium for culture of Lactobacillus. Afr. J. Biotechnol. 16(30):1630-1637.

2. Brantes, P. (2011). Diseño de un Medio de Cultivo Alternativo para la Cepa Láctica BAL-C Productora de una Sustancia Tipo Bacteriocina (STB) Inhibitoria de Listeria monocytogenes. Tesis de la Universidad Austral de Chile, Escuela de Ingeniería en alimentos. Valdivia. pp 62.

3. Bujalance, C., Jiménez-Valera, M., Moreno, E. \& Ruiz-Bravo, A. (2006). A selective differential medium for Lactobacillus plantarum. Journal of Microbiological Methods. 66:572-575.

4. Bu, M., Sánchez, N., Perez-Saad, H., Lara, G. \& Scull, I. (2011). Efecto neurofarmacológico del zumo de Morinda citrifolia. Boletín Latinoamericano y del Caribe de Plantas Medicinales y Aromáticas. 10(2):159-166. 
5. Buriti, F., Komatsu, T. \& Saad, S. (2007). Activity of passion fruit (Passiflora edulis) and guava (Psidium guajava) pulps on Lactobacillus acidophilus in refrigerated mousses. Brazilian Journal of Microbiology. 38(2):315-317.

6. Casado, M., Torrico, G. \& Medina, M. (2012). Medios de cultivo en un laboratorio de microbiología. Disponible en: https://libroslaboratorio.files.wordpress.com/2012/09/medios-decultivo-en-un-laboratorio-de-microbiologc3ada.pdf.

7. Chanson-Rolle, A., Braesco, V., Chupin, J. \& Bouillot, L. (2016) Nutritional Composition of Orange Juice: A Comparative Study between French Commercial and Home-Made Juices. Food and Nutrition Sciences. 7:252-261.

8. Chen, H., Niu, J., Qin, T., Ma, Q., Wang, L. \& Shu, G. (2015). Optimization of the medium for Lactobacillus acidophilus by PlackettBurman and steepest ascent experiment. Acta Sci. Pol. Technol. Aliment. 14(3):227-232.

9. Corona, A. \& Jiménez R. 2004. Comparación de dos métodos de siembra para el recuento de microorganismos en muestras con alta concentración microbiana. Revista de la Facultad de Ingeniería Química. 40:3-7.

10. Djeghri-Hocine, B., Boukhemis, M. \& Amrane, A. (2010). Formulation and evaluation of a selective medium for lactic acid bacteria-validation on some dairy products. American Journal of Agricultural and Biological Sciences. 5(2)148-153.

11. Di Lena, M., Quero, G., Santovito, E., Verran, J., De Angelis, M. \& Fusco, V. (2015). A selective medium for isolation and accurate enumeration of Lactobacillus casei-group members in probiotic milks and dairy products. International Dairy Journal. 47:27-36.

12. Forrellat, M., Fernández N., Gautier H. \& Benítez D. (2004). Modificación de un medio de cultivo para la determinación de folatos. Rev Cubana Hematol Inmunol Hemoter. 20(1).

13. Hartemink, R., Domenech V. \& Rombouts R. 1997. LAMVAB, a new selective medium for the isolation of lactobacilli from faeces. J. Microbiol. Methods. 29:77-84.

14. Hours, R., Ferreyra M., Schvab M., Gerard L., Zapata L. \& Davies C. (2005). Caracterización fisicoquímica y microbiológica de jugos de naranja destinados a vinificación. Ciencia, Docencia y Tecnología. 16(31):219-239.

15. Islam, R. (2013). Bifidogenic effect and the immunity power of human breast milk. Delta Med Col J. Jan. 1(1):20-24. 
16. Jerez, A., Díaz de Oropeza, R., Vargas, M. \& Ramírez N. (2017). Estudio de las propiedades benéficas en la cebolla (Allium cepa L.) en el departamento de Tarija. Rev. Vent. Cient. 8(13):7-12.

17. Lara, C. (2008). Composición química de un medio de cultivo a partir de guayaba agria (Psidium araca) y su relación con la nutrición de los microorganismos ruminales. Revista Colombiana de Biotecnología. 10(2):44-49.

18. Lima, K., Kruger, M., Behrens, J., Destro, M., Landgraf, M. \& Gombossy, B. (2009). Evaluation of culture media for enumeration of Lactobacillus acidophilus, Lactobacillus casei and Bifidobacterium animalis in the presence of Lactobacillus delbrueckii subsp bulgaricus and Streptococcus thermophiles. LWT Food Science and Technology. 42:491-495.

19. León-de la O, D., Calderón-Yépez, B., Martínez-Ballinas, A., Sánchez-Herrera, E., Zulatto-Lobato, A., Camacho-Hernández, I., Arredondo-Villanueva A. \& Salgado-Brito, R. (2013). Formulación y optimización de un medio de cultivo económico para Lactobacillus con potencial probiótico aislado del pulque. Investigación Universitaria Multidisciplinaria. 12(12):133-144.

20. Liguori, L., Califano, R., Albanese, D., Raimo, F., Crescitelli, A. \& Di Matteo, M. (2017). Chemical composition and antioxidant properties of five white onion (Allium cepa L.) landraces. Journal of Food Quality. 2017:1-9.

21. Lopes, S. \& Torres, S. (2006). An Effective and Low-Cost Culture Medium for Isolation and Growth of Xylella fastidiosa from Citrus and Coffee Plants. Current Microbiology. 53:467-469. DOI: 10.1007/s00284-005-0477-0

22. Man, J., Rogosa M. \& Sharpe M. 1990. A medium for the cultivation of lactobacilli. J. Appl. Bacteriol. 32:130-135.

23. Marcia, E., Malespín, J., Sánchez, M. \& Benavente, M. (2011). Estudio de la fermentación láctica para la extracción de quitina a partir de desechos de crustáceos. Nexo Revista Científica. 24(1):33-42.

24. Moreno, M., Belen D., García D. \& Mendoza L. (2006). Evaluación del contenido de carotenoides totales en cáscaras de algunas variedades de naranjas venezolanas. Revista de la Facultad de Agronomía-LUZ. 23(3):301-309.

25. Nath, A., Mondal, S., Csighy, A., Molnár, M., Pásztorné-Huszár, K., Kovács, Z., Koris, A. \& Vatai, G. (2017). Biochemical activities of lactose-derived prebiotics - A review. Acta Alimentaria. 46(4):449456. 
26. NMX-FF-021-1986. Productos alimenticios no industrializados para consumo humano. Tubérculo cebolla (Allium cepa L.). Especificaciones.

27. NMX-FF-025-SCFI-2007. Productos alimenticios no industrializados para consumo humano. Chile fresco (Capsicum spp). Especificaciones.

28. NORMEX, Sociedad Mexicana de Normalización y Certificación. 2002. PROYNMX-F-602-1999-NORMEX. Alimentos, bebidas no alcohólicas y jugos envasados. Apéndice B.

29. Olivas, E. \& Alarcón L. 2004. Manual de prácticas de Microbiología básica y Microbiología de alimentos. Universidad Autónoma de Ciudad Juárez, Instituto de Ciencias Biomédicas. Academia de Microbiología y Parasitología. Editorial: Ciudad Juárez, Chihuahua, México: Universidad Autónoma de Ciudad Juárez. p 39.

30. Pathak, M. \& Martirosyan, D. (2012). Optimization of an effective growth medium for culturing probiotic bacteria for applications in strict vegetarian food products. Functional Foods in Health and Disease. 2(10):369-378.

31. Rosenblatt, J. \& Stewart P. 1975. Anaerobig bag culture method. Journal of Clinical Microbiology. 1(6)527-550.

32. Rojas, A., Montaño, L. \& Bastidas, M. (2015). Producción de ácido láctico a partir del lactosuero utilizando Lactobacillus delbrueckii subsp. bulgaricus y Streptococcus thermophilus. Rev. Colomb. Quim. 44(3):5-10.

33. Sáenz, A. \& D'Alolio, O. (2007). Identificación de pérdidas poscosecha de chile jalapeño [Capsicum annum 1. cultivar mitla] para uso agroindustrial. Consejo Nacional de Producción. San José (Costa Rica). 25 p.

34. Silva, A., Cortés C. \& Yahuaca B. (2006). Evolución de indicadores de calidad de guayaba almacenada en frigorífico. Revista DES. 1(2006):5-11.

35. Shafakatullah, N. \& Chandra, M. (2015). Isolation of lactic acid bacteria from Allium cepa var. aggregatum and study of their probiotic properties. International Journal of Pharma Sciences and Research (IJPSR). 6(4):749-757.

36. Tabasco, R., Paarup, T., Janer, C., Peláez, C. \& Requena, T. (2007). Selective enumeration and identification of mixed cultures of Streptococcus thermophilus, Lactobacillus delbrueckii subsp. bulgaricus, L. acidophilus, L. paracasei subsp. paracasei and Bifidobacterium lactis in fermented milk. International Dairy Journal. 17:1107-1114. 
37. Tamime, A., Marshall-Valerie M. \& Robinson R. 1995. Microbiological and technological aspects of milks fermented by bifidobacteria. J. Dairy Res. 62:151-187.

38. Ugarte, M., Scollo D., Giraudo M., Menéndez J. \& Sánchez, H. (2011). Disacáridos funcionales: lactulosa, lactitol y lactosa. Actualización en Nutrición. 12(3):216-223.

39. Ulloa, J., Rosas P., Ramírez J. \& Ulloa B. 2012. El noni: propiedades, usos y aplicaciones potenciales. Revista Fuente. 4(10):44-49.

40. Urcia, F. \& Guevara M. 2002. Eficacia de medios de cultivo con infusiones de variedades de papa en la identificación del Trichophyton rubrum. Rev Peru Med Exp Salud Pública. 19(4):206-208.

41. Zapata, I., Sepúlveda-Valencia, U. \& Rojano, B. (2015). Efecto del tiempo de almacenamiento sobre las propiedades fisicoquímicas, probióticas y antioxidantes de yogurt saborizado con mortiño (Vaccinium meridionale Sw). Información Tecnológica. 26(2):17-28. 